\title{
DESIGN AND RESEARCH ON THE INTELLIGENT SYSTEM OF URBAN RAIL TRANSIT PROJECT BASED ON BIM+GIS
}

\author{
YAN LIU, MOHD ASIF SHAH† ANTON PLJONKIN $\ddagger$ MOHAMMAD ASIF IKBAL $\$$ AND MOHAMMAD SHABAZ
}

\begin{abstract}
Building Information Modeling (BIM) technology has been widely used in the construction industry, especially in the field of civil construction. BIM standards, basic software and management platforms are relatively mature. The urban rail transit projects are linear projects, they not only span long lines, multiple regions, involve multiple disciplines, and are difficult to coordinate, but also have complex surrounding environments and high safety requirements. Therefore, their needs for integrated construction and operation applications are more concentrated. In order to solve the problems of data isolation, single display form, abnormal situation notification and delayed processing in urban rail transit construction monitoring, combined with GIS+BIM technology, a complete set of construction monitoring information management process and data organization plan is proposed, and the development is oriented. The construction monitoring system of project construction management focuses on solving the problems of the integration, display, early warning and secondary early warning of construction monitoring data.The system realizes the functions of input, storage, processing, three-dimensional display and early warning of measuring point information and daily measurement information. It is integrated with the GIS+BIM management and control platform, and the project is carried out in the construction project of Qingdao Rail Transit Line 8. Application, interact with functions such as model browsing, schedule control, engineering quantity management, video monitoring, etc., to improve the management efficiency and safety quality level of on-site construction. The mainstream GIS and BIM data based research on construction monitoring data standards promote the in-depth integration of construction monitoring data and improve the data entry and association efficiency.
\end{abstract}

Key words: Building Information Modeling, Urban rail transit; construction monitoring; GIS; integration; linear projects; multiple regions.

AMS subject classifications. 94-10

1. Introduction. Concealed projects such as urban rail transit, underground complexes, and underground pipe corridors are very different from above-ground projects due to their construction conditions and construction methods. Construction units need to understand construction monitoring data in a timely manner during the construction process, such as: surface deformation, structural settlement, structure Horizontal displacement, supporting internal forces, etc [1]. At present, BIM technology has been widely used in the construction industry in my country, especially in the field of civil construction. BIM standards, basic software and management platforms are relatively mature. Because urban rail transit projects are linear projects, they not only span long lines, multiple regions, involve multiple disciplines, and are difficult to coordinate, but also have complex surrounding environments and high safety requirements. Therefore, their needs for integrated construction and operation applications are more concentrated as shown in Figure 1.1. However, at this stage, there are still many problems in the application of BIM technology in urban rail transit projects:

1. The basic BIM software for urban rail transit projects is not yet mature and has not formed a unified data standard.

2. The construction of urban rail transit projects involves many environmental factors and conditions. Complex, traditional BIM technology cannot integrate all data information.

3. The large amount of BIM model data, model lightweight technology and mobile internet technology are backward, which limits its convenient application in design and construction.

${ }^{*}$ KDGX International Education and Humanities College, Xi'an Kedagaoxin University, Shaanxi, 710109 China (Yanliu111@ outlook.com).

$\dagger^{\dagger}$ Bakhtar University, Kabul, Afghanistan (ohaasif@bakhtar.edu.af).

¥Southern federal University, Russia (pljonkin@mail.ru).

$\S$ School of Electronics and Electrical Engineering, Lovely Professional University, Punjab, India (asif.22797@lpu.co.in).

『Abra Minch University, Ethiopia (Mohammad.shabaz@amu.edu .et). 


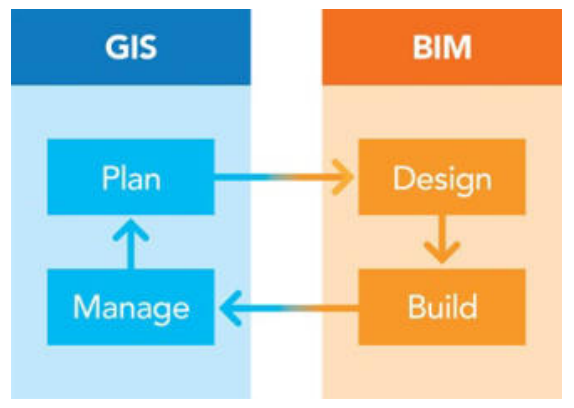

FIG. 1.1. Integration of BIM and GIS

There are three modules in the simulation model of urban rail transit safety vulnerabilities. The first unit: urban track traffic can respond to interference in time and perform corresponding adjustments and adaptation. Module 2: Urban rail transit can be restored to a completely normal state to implement some interference. Module 3: Urban track traffic can be completed within a limited self-recovery and adjustment time, and the vulnerable state after the period of disturbance can restore normal state in time. Most of the existing construction monitoring systems focus on solving the problems of data organization and business process, lack of association with other information in construction, and do not put forward the complete process of data input, calculation, display, early warning, message push, early warning processing and so on [2, 3].The main problems are:

1. The data entry is cumbersome, and the paper data or Excel tables used on site cannot be seamlessly connected with the system, resulting in the system data entry is not timely.

2. The system display and data query are mostly two-dimensional drawings and data charts. Mainly, it has high technical requirements for system users and is not intuitive enough.

3. The data (such as: wrong data, measurement points that are again for early warning after an early warning, etc.) are not specially processed on the construction site $[4,5]$.

The existing construction monitoring system has not fully played its role in construction safety management. Based on scholars' research on GIS, BIM, and construction monitoring information technology, a reliable and efficient construction monitoring system should have the following characteristics:

1. High integration of construction monitoring data and progress data, surrounding buildings, geological data, etc.

2. Data The diversification of queries.

3. The multi-angle and intuitiveness of data display.

4. The processing of abnormal data and the immediacy of pushing early warning messages.

The important modes of urban commuter transport are urban rail transit that can operate at higher speeds than buses typically utilized in traditional transport systems. The unexpected disruptions are caused by the urban rail transit line emergencies which lead to interrupted operations and passenger delays. Unexpected service disruptions of varying degrees are caused by the variety of random events ranging from train malfunctions to bomb threats and power failures $[6,7]$. The longer disruptions are caused by the serious emergencies whereas the short disruptions are caused by the minor events. The rail transit system reliability is ensured by the evacuation for emergency plan. The interactive collaboration between the different professionals is the BIM methodology's fundamental feature to insert, extract, and modify the model information. A single virtual model is recreated in the iterative process which contains the series of additional or complementary information of the elements of the dimensional structure, costs, safety and decommissioning.

The organization of the paper is as follows. Section 2 provides an overview of the exhaustive literature survey followed by a methodology adopted in section 3. A detailed discussion of obtained results is in section 4. Finally, section 5 concludes the paper.

2. Literature Review. In order to overcome the vulnerability of large passenger flow effects, WANG, L. et al. proposed improvement method based on large passenger vulnerability and applied five-year passenger 
flow technology. There are three modules in the simulation model of urban rail transit safety vulnerabilities. The first unit: urban track traffic can respond to interference in time and perform corresponding adjustments and adaptation. Module 2: Urban rail transit can be restored to a completely normal state to implement some interference. Module 3: Urban track traffic can be completed within a limited self-recovery and adjustment time, and the vulnerable state after the period of disturbance can restore normal state in time [8].

Many City Rail Transit (URT) systems use DC traction power systems. Since the impedance and incomplete ground insulation of the running track, a portion of the traction current is inevitable to flow from the track into the ground, resulting in stray current. This type of current will produce huge safety hazards in the URT system and nearby metal structures. Yao, C. et al. explores different resistors in each of the power supplies under each power supply section below the bilateral power supply. Then, the defect of the current discharge method was identified in the context of stray current protection. In order to solve these defects, a reverse chemical neural network (bpnn) is used to construct the discharge flow prediction model. On this basis, a smart current monitoring system is established for the URT. Finally, the author simulates the effect of each factor on the stray current and verifies the reliability and stability of the proposed monitoring system. Compared with the predicted value and the actual value, the prediction agreement is very good $[9,10]$.

Based on GIS and BIM technology, combined with the actual needs of the project site, this paper establishes a comprehensive project construction management and control system, which integrates construction monitoring and progress management, engineering quantity management, video monitoring, shield monitoring and other modules, in order to realize the convenience of construction monitoring data. Processing, diversified inquiries, multi-angle display, rapid warning, improve the level and efficiency of project quality and safety management [11].

The alleviation of urban traffic congestion is an efficient way with the development of urban roads. The site space, complex resource allocation and tight schedule are limited [12]. These technical problems are solved by the BIM technology, three-dimensional visualization and parameterization. Throughout the lifecycle of BIM technology, BIM technology is innovatively researched in the context of the metro rail transit project. The optimum construction scheme of the shield machine is determined by the model information file which is imported for $4 \mathrm{D}$ simulation. The engineering quality and construction efficiency of the subway rail transit project is improved by the BIM technology. In this paper, author develops a project on Building Information Model (BIM)-based monitoring system for monitoring data integration and visualization for risk assessments [13]. A construction project and a comprehensive model are established by utilizing the BIM technology. The intelligent building components are composed into it which includes the parametric rules for each object. The construction project team is provided by the system with ongoing project. The possible blind spots when attempting to achieve risk assessments are identified by the construction project teams and further enable the adoption of mitigation measures to reduce risk levels.In the context of transportation infrastructure, BIM technology utilization is slow although in building industry, it has been widely adopted [14]. BIM for other non-building civil infrastructure is now adopting in industry and academia. Author in this paper implement the BIM technology in in an infrastructure design project. The focus of the paper is also on specific road elements modeling from guardrails and retaining walls etc. by utilizing the Revit and Subassembly Composer and the interoperability is also analyzed among BIM-based tools. In this paper, the unfavorable effects are caused by the deep excavations in urban areas on ground stability [15]. The environmental impact is required to evaluate and monitor during deep excavation construction processes. All the monitoring instruments are setup by the construction project team for controlling and monitoring the environmental status during the construction of retaining walls. The Building Information Model (BIM)-based monitoring system is developed in this paper by the author for monitoring data integration and visualization. The transit-based evacuations under emergency scenarios are focused by the author in this paper on single rail line under emergency scenarios. The stranded passenger's evaluation is done by the model which determines the vehicles and routes. The optimization model is proposed in this paper for maximizing the total number of stranded passengers within the given time window [16]. The validation of the proposed model and optimization model is done. The proposed control method effectiveness is evaluated and the stranded passengers at stations are analyzed under different numbers of vehicles. The routing arrangements are provided by the proposed model to maximize the number of passengers.

2.1. Contribution. Present the technique to solve the problems of data isolation, single display form, 


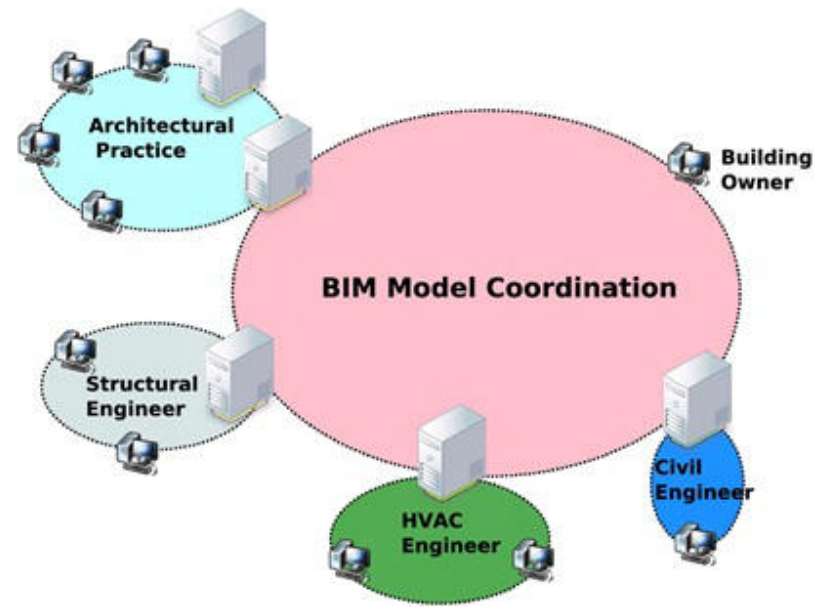

FIG. 3.1. BIM model

abnormal situation notification and delayed processing in urban rail transit construction monitoring, combined with GIS+BIM technology. A complete set of construction monitoring information management process and data organization plan is proposed, and the development is oriented. The construction monitoring system of project construction management focuses on solving the problems of the integration, display, early warning and secondary early warning of construction monitoring data. The system realizes the functions of input, storage, processing, three-dimensional display and early warning of measuring point information and daily measurement information.

\section{System Design.}

3.1. System Architecture. The system mainly serves the construction party and meets the application requirements including: three-dimensional display, historical data query, data import and export, monitoring and early warning, early warning processing and secondary early warning. The system uses a layered architecture, and the data uses a centralized storage method [17, 18]. BIM data services, high-definition terrain services, and monitoring-related data services are provided by the central server. The basic terrain services use the Sky Map of the National Geographic Information Public Service Platform. The BIM model is shown in Figure 3.1.

3.2. The correlation of monitoring data with GIS and BIM data. In the development of digital tunnels to smart tunnels, the comprehensive interconnection and deep integration of data and systems are important manifestations. The interrelationship of monitoring points, structural components, and surrounding environments will greatly increase the convenience and diversity of data query and display. Monitoring points can be broadly divided into structural monitoring, surface monitoring and environmental monitoring according to their spatial location $[19,20]$. Among them, structural monitoring points are associated with components, and surface monitoring is associated with the ground. Environmental monitoring is mainly associated with GIS data through user-specified three-dimensional coordinates [21-24]. The incorporation of site data in BIM environment is shown in Figure 3.2.

When the user enters the measuring point for the first time, the type of measuring point, monitoring items and plane coordinate values (X, Y) are specified. For structural monitoring points, the system has a built-in relationship table to realize the association between different monitoring items and component types [25]. The monitoring points are orthographically projected in the vertical direction according to the plane coordinates, looking for components under this type, and determining a unique associated component. And get the component GUID number and the $\mathrm{Z}$ coordinate of the monitoring point; for surface monitoring, the system will project the measuring point to the surface to obtain the $\mathrm{Z}$ coordinate; For environmental monitoring, the user must manually specify the $\mathrm{Z}$ coordinate of the measuring point. Surface monitoring and environmental 


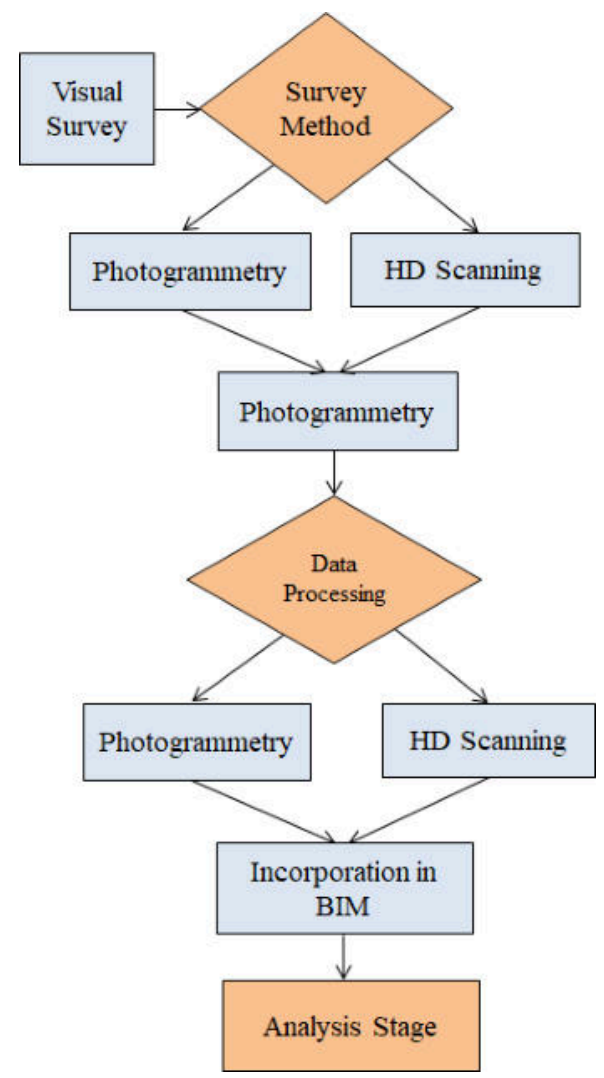

FIG. 3.2. The incorporation of site data in BIM environment

monitoring points are not related to components [26, 27].

4. Results and discussion with function application system. The function application and entrance are mainly set according to the working habits of the engineering personnel, which are more redundant and complicated. Only the core functions are explained below.

4.1. Data Entry. Because engineering monitoring personnel have a large amount of data processing work every day, the system should provide simple and quick entry mode when designing data entry modules, and provide the monitoring personnel with intuitive and referable data inspection results. All data entry in this system supports single-line entry and imported Excel table entry. The user customizes the system entry template according to the on-site data table format to achieve the purpose of seamless connection between on-site data and the system [28, 29]. After entering daily data, a temporary interface for data inspection is provided. The inspection content includes whether the measured value and the rate of change exceed the limit, whether the corresponding monitoring point exists, whether there is an early warning for the measuring point, etc. The user can directly review and edit the data in the temporary interface. The monitoring data entry check is shown in Table 4.1.

4.2. Early warning and handling. In the existing construction monitoring and early warning, there are mainly the following problems:

1. The single prediction is mainly based on the measured value.

2. The monitoring and early warning in the actual construction is a complex and cyclical process. After the monitoring data exceeds the limit, it is also accompanied by early warning processing.

3. More than $50 \%$ of the monitoring data in all regions of the country are in a state of exceeding the control value, and the early warning processing is seriously lagging behind [30,31]. Combining industry 
TABLE 4.1

Monitoring data entry check

\begin{tabular}{||l|l|l|l|l|l|l||}
\hline $\begin{array}{l}\text { Line } \\
\text { number }\end{array}$ & $\begin{array}{l}\text { Repeated measu- } \\
\text { ring points }\end{array}$ & $\begin{array}{l}\text { Test } \\
\text { group }\end{array}$ & $\begin{array}{l}\text { Measuring } \\
\text { point }\end{array}$ & $\begin{array}{l}\text { Measured } \\
\text { value }\end{array}$ & $\begin{array}{l}\text { Cumulative } \\
\text { change state }\end{array}$ & $\begin{array}{l}\text { Rate change } \\
\text { status }\end{array}$ \\
\hline \hline 1 & normal & 2 & 4 & 9 & normal & normal \\
\hline 2 & normal & 2 & 4 & 3 & normal & normal \\
\hline 3 & normal & 2 & 4 & 12 & normal & normal \\
\hline 4 & normal & 2 & 4 & 11 & normal & normal \\
\hline 5 & normal & 2 & 4 & 7 & normal & normal \\
\hline 6 & normal & 2 & 4 & 8 & normal & normal \\
\hline 7 & normal & 2 & 4 & 12 & normal & normal \\
\hline
\end{tabular}

TABLE 4.2

Early warning rules

\begin{tabular}{||l|l||}
\hline Warning status & Monitoring value size \\
\hline \hline Yellow warning & $\begin{array}{l}\text { The cumulative value and rate both reach } 70 \% \text { of the limit, or a certain value } \\
\text { reaches } 85 \% \text { of the limit }\end{array}$ \\
\hline Orange warning & $\begin{array}{l}\text { The cumulative value and rate both reach } 85 \% \text { of the limit, or a certain value } \\
\text { reaches } 100 \% \text { of the limit }\end{array}$ \\
\hline Red alert & Both the cumulative value and the rate reach $100 \%$ of the limit \\
\hline
\end{tabular}

standards and local standards, this system adopts dual-control indicators and three-level early warning.

The early warning rules are shown in Table 4.2 .

At the measuring point after the limit, if there is a warning again, regardless of the level, the warning should be paid enough attention. Therefore, the system defines all such early warnings as "secondary early warning", which is the highest level of early warning in the system.After the warning occurs, the message is immediately pushed to the relevant users [32]. At this time, the site monitoring engineer must deal with the warning in time to stop the push of warning messages. When the yellow and orange warnings are processed, the user only needs to enter the warning measuring point and click the button "complete the warning processing"; when the red warning and the second warning are processed, the system also provides the function of modifying the warning limit to meet the requirements. The need to re-approve the warning limit after a high-level warning occurs at the measuring point. It should be noted that the "processing completion" of the warning in the system means that the monitoring engineer understands the warning message of the measuring point and submits it for approval to complete the relevant offline processing process; after the red warning occurs at the measuring point, if the warning limit needs to be re-approved the value must be uploaded along with the scanned copy of the offline submission documents.

4.3. Data display system. The $\mathrm{C} / \mathrm{S}$ terminal mainly provides the following functions: Three-dimensional display, data charts and early warning functions. The three-dimensional interface and related annotations are shown in Table 4.3 .

It provides 3 display modes: The maximum value statistics of the day, survey point overview, and early warning query. When switching between modes, the measuring point data displayed in the 3D view is automatically switched. The measuring points in the 3D view are displayed in the form of icons + labels, and the relevant information includes the measuring point name, the latest cumulative value and the latest speed value. The color of the text marked on the measuring point indicates the different status of the measuring point, and the meaning is shown in Table 4.4 .

4.4. Engineering application examples: Project overview. This system was applied on a pilot basis in the Qingdao Metro Line 8 Dayang Station-Qingdao North Station Interval (Subsea Tunnel) and integrated in the GIS+BIM project management and control platform. The Dayang Station-Qingdao North Station Interval 
TABLE 4.3

The $3 D$ interface and related annotations

\begin{tabular}{||l|l|l|l|l|l|l||}
\hline Monitoring items & $\begin{array}{l}\text { Latest mea- } \\
\text { sured value }\end{array}$ & $\begin{array}{l}\text { Cumulative } \\
\text { value }\end{array}$ & Rate value & $\begin{array}{l}\text { Upper } \\
\text { limit }\end{array}$ & $\begin{array}{l}\text { Lower } \\
\text { limit }\end{array}$ & $\begin{array}{l}\text { Lower limit of rate } \\
\text { value }\end{array}$ \\
\hline \hline Land subsidence & $-2.22 \mathrm{~mm}$ & $-2.22 \mathrm{~mm}$ & $-0.25 \mathrm{~mm} / \mathrm{d}$ & $30 \mathrm{~mm}$ & $-30 \mathrm{~mm}$ & $-3 \mathrm{~mm} / \mathrm{d}$ \\
\hline Land subsidence & $-3.53 \mathrm{~mm}$ & $-3.53 \mathrm{~mm}$ & $-1.22 \mathrm{~mm} / \mathrm{d}$ & $30 \mathrm{~mm}$ & $-30 \mathrm{~mm}$ & $-3 \mathrm{~mm} / \mathrm{d}$ \\
\hline Land subsidence & $-3.59 \mathrm{~mm}$ & $-3.59 \mathrm{~mm}$ & $-0.82 \mathrm{~mm} / \mathrm{d}$ & $30 \mathrm{~mm}$ & $-30 \mathrm{~mm}$ & $-3 \mathrm{~mm} / \mathrm{d}$ \\
\hline Land subsidence & $-3.33 \mathrm{~mm}$ & $-3.33 \mathrm{~mm}$ & $-2.11 \mathrm{~mm} / \mathrm{d}$ & $30 \mathrm{~mm}$ & $-30 \mathrm{~mm}$ & $-3 \mathrm{~mm} / \mathrm{d}$ \\
\hline Land subsidence & $-3.3 \mathrm{~mm}$ & $-3.3 \mathrm{~mm}$ & $-0.59 \mathrm{~mm} / \mathrm{d}$ & $30 \mathrm{~mm}$ & $-30 \mathrm{~mm}$ & $-3 \mathrm{~mm} / \mathrm{d}$ \\
\hline Land subsidence & $-2.5 \mathrm{~mm}$ & $-2.5 \mathrm{~mm}$ & $0.86 \mathrm{~mm} / \mathrm{d}$ & $30 \mathrm{~mm}$ & $-30 \mathrm{~mm}$ & $-3 \mathrm{~mm} / \mathrm{d}$ \\
\hline Land subsidence & $-2.46 \mathrm{~mm}$ & $-2.46 \mathrm{~mm}$ & $-0.11 \mathrm{~mm} / \mathrm{d}$ & $30 \mathrm{~mm}$ & $-30 \mathrm{~mm}$ & $-3 \mathrm{~mm} / \mathrm{d}$ \\
\hline Land subsidence & $-4.25 \mathrm{~mm}$ & $-4.25 \mathrm{~mm}$ & $0.67 \mathrm{~mm} / \mathrm{d}$ & $30 \mathrm{~mm}$ & $-30 \mathrm{~mm}$ & $-3 \mathrm{~mm} / \mathrm{d}$ \\
\hline
\end{tabular}

TABLE 4.4

Text color meaning

\begin{tabular}{||l|l||}
\hline Color & Meaning \\
\hline \hline White & Normal \\
\hline Green & Maximum rate in the test group \\
\hline Dark green & The maximum accumulated value in the test group \\
\hline yellow & Yellow warning \\
\hline Orange & Orange warning \\
\hline Red & Red alert \\
\hline Crimson & Second warning \\
\hline
\end{tabular}

Line starts from Dayang Station in Chengyang District, goes eastward along Aodongnan Road and crosses the Hedong Road ramp bridge, enters the sea on the east side of the bridge Hongdao toll station, and the section passes through the sea area of Jiaozhou Bay, and then connects Qingdao North Station in Qingdao (see Figure 4.1).This section is an important node project of Qingdao Metro Line 8. It is a double-hole single-line tunnel with a total length of about $8.1 \mathrm{~km}$, and a length of about $5.5 \mathrm{~km}$ across the sea. It is mainly constructed by mining method and shield method. The interval includes 1 inclined shaft, 3 wind shafts, 1 shield section, 1 mining method section, and 1 open-cut section. In the initial stage, 1,000 monitoring points have been deployed, and the total number of points is expected to be about 2,000. The main monitoring the items include surface deformation, dome settlement, convergence deformation, pile top displacement and blasting vibration velocity.

4.5. Engineering Application. Relying on the "Qingdao Metro Line 8 Project Information Management and Control Platform", the construction monitoring subsystem is integrated to realize the functions of monitoring data management, display, processing, export, early warning messages, and secondary early warnings; it realizes the authority management of data. Data is divided according to different work points and different levels of personnel to control the visibility and editability of the data. The project construction system is shown in Figure 4.2.

The system can realize the functions of data curve drawing at any time of single and multiple measuring points, historical data query of measuring points, early warning processing and message push.After the construction monitoring system is integrated in the GIS+BIM platform, all data can be displayed and queried on the three-dimensional interface, including:

1) The type of measuring point, the relative spatial relationship between the measuring point and the terrain and structures, the display of the measured value, the warning state, etc.

2) After the management personnel discover the abnormal data of construction monitoring, they can immediately call the surrounding cameras to check the on-site environment, call the progress management 


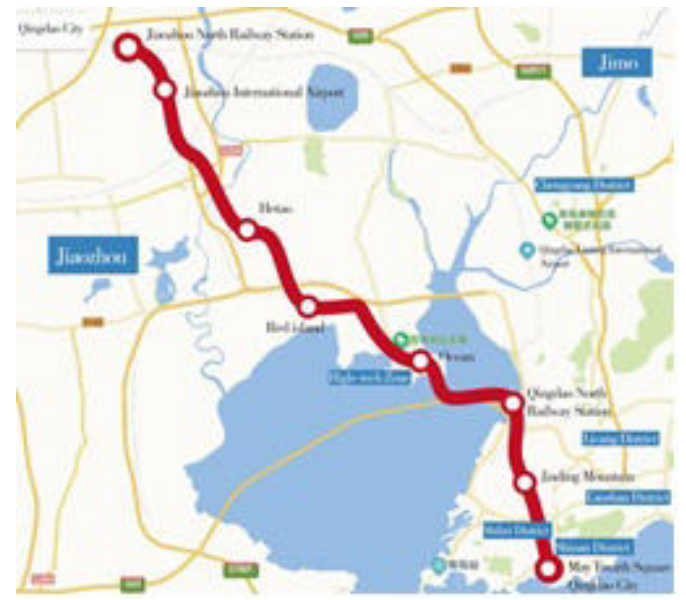

FIG. 4.1. Qingdao Rail Transit Line 8

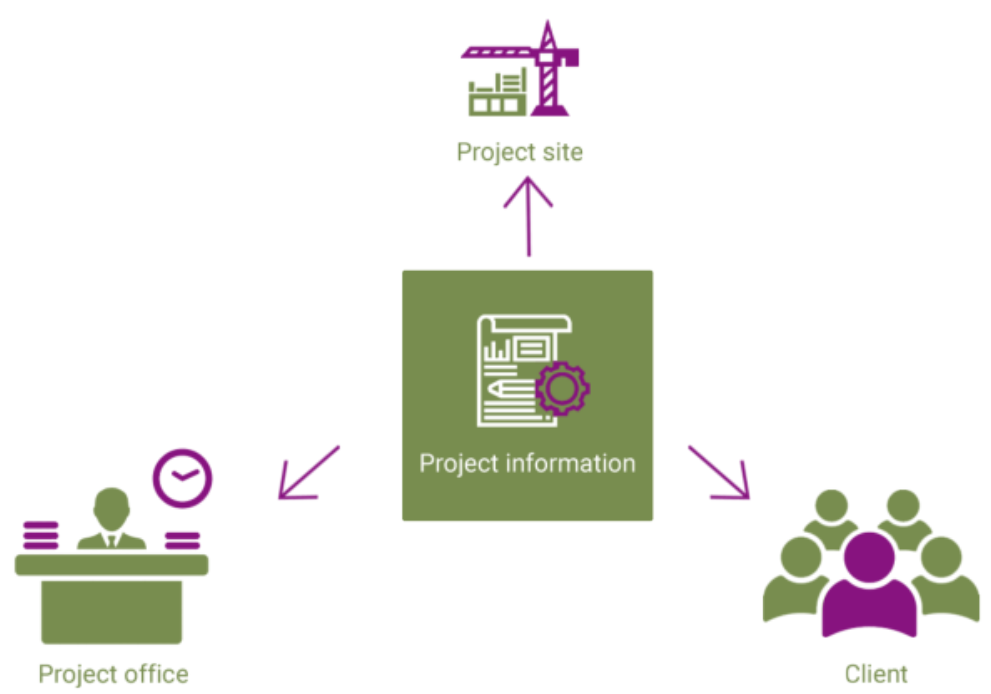

FIG. 4.2. The project construction system

system and the shield machine management system to check whether the recent construction status is abnormal.

3) Provide the monitoring data space query function, which can be batched View the monitoring data in a certain area, draw a graph for horizontal comparison, and improve the efficiency of abnormal data analysis. The main function applications are shown in Fig 4.3.

From the perspective of engineering construction management, the data organization plan, functional process and functional application are proposed, and the construction monitoring system is designed, and the system has been verified in actual construction management.This article introduces the core ideas and key links of the system in more detail. The main results are as follows.

1) Put forward a relatively complete monitoring data organization structure, develop a construction monitoring management system based on engineering practice, and realize the whole process management of construction monitoring data.

2) This paper puts forward the functional structure of the construction monitoring system suitable for site construction management. The system provides the core functions of monitoring data input, processing, inquiry, display, early warning and secondary early warning, early warning processing, and achieves the purpose 


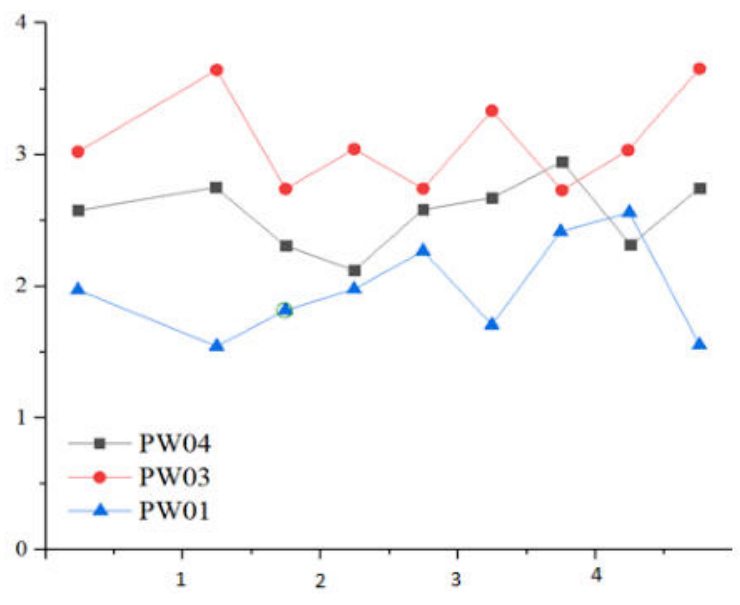

FIG. 4.3. Multi-point curve diagram

of flow, standardization and traceability of field monitoring data processing.

3) The construction monitoring data is associated with GIS and BIM data, and the system is integrated with the GIS+BIM management and control platform. It provides intuitive and diverse data display and query functions, and solves the problems of data flow, fast browsing, and instant warning in construction monitoring management.

5. Conclusion. With the rapid iteration of information technology and the emergence of new equipment and new technologies, the author believes that there are the following possible research directions in the development of construction monitoring systems. Introduce image recognition and machine learning technology to automatically recognize and enter the large-scale use of paper and manual data on the project site to solve the current difficulty in data entry in the construction monitoring system. The integration of construction monitoring Internet of Things equipment with construction monitoring systems and GIS and BIM technologies mainly includes the structuring of multi-source heterogeneous data, the unification of data structures and communication protocols, etc., to ensure that the data volume and throughput requirements are greatly increased. The integration of the construction monitoring system with the lightweight GIS and BIM engine makes the system suitable for mobile devices under the premise of ensuring the complete and efficient system functions. Research on the in-depth integration of construction monitoring, BIM and mechanical analysis, using construction monitoring data to back calculate the structure and stratum deformation and internal force data, and display the real-time deformation and internal force of the structure and stratum in the form of three-dimensional cloud diagrams to reflect the safety status of the project in real time. Research on construction monitoring data standards based on mainstream GIS and BIM data standards to promote the in-depth integration of construction monitoring data with GIS and BIM data, and to improve the efficiency of data entry and association.

\section{REFERENCES}

[1] Man, L., Ywabc, D., LJABC, D., YC, B., Risk propagation analysis of urban rail transit based on network model, Alexandria Engineering Journal, 59( 3), 1319-1331, 2020.

[2] Zhang, N., Chen, F., Y Zhu, H Peng, Y Li. , RA study on the calculation of platform sizes of urban rail hub stations based on passenger behavior characteristics, Mathematical Problems in Engineering, 7, 1-14, 2020.

[3] Li, S., Wu, S., Xiang, S., Zhang, Y., Guerrero, J. M., Vasquez, J. C. , Research on synchronverter-based regenerative braking energy feedback system of urban rail transit, Energies, 13(17), 4418, 2020.

[4] Ding, L. Y., Zhou, Y., Luo, H. B., Wu, X. G., Using nD technology to develop an integrated construction management system for city rail transit construction, Automation in Construction, 21, 64-73, 2012.

[5] Dong, L., Wu, J., ZHOU, Y., WANG, W. , Visualization of Foundation Evaluation for Urban Rail Transit Based on CGB Technology Integration, International Journal of Sustainable Development and Planning, 15(4), 477-486, 2020.

[6] Wang, G., Zhang, Z. , BIM implementation in handover management for underground rail transit project: A case study approach, Tunnelling and Underground Space Technology, 108, 103684, 2021. 
[7] Xu, X., Wang, G., CaO, D., Zhang, Z. , BIM Adoption for Facility Management in Urban Rail Transit: An Innovation Diffusion Theory Perspective, Advances in Civil Engineering, 2020.

[8] Wang, L., Chen, Y., Wang, C. , Research on evolutionary model of urban rail transit vulnerability based on computer simulation, Neural Computing and Applications, 32(1), 195-204, 2020.

[9] Yao, C., Zhao, Q., Ma, Z., Zhou, W., YaO, T, Design and simulation of an intelligent current monitoring system for urban rail transit, IEEE Access, 8, 35973-35978, 2020.

[10] Elsheikh, A., Alzamili, H. H., Al-Zayadi, S. K., Alboo-Hassan, A. S., Integration of GIS and BIM in Urban Planning-A Review, In IOP Conference Series: Materials Science and Engineering (Vol. 1090, No. 1, p. 012128). IOP Publishing, 2021.

[11] Olawumi, T. O., Chan, D. W., Wong, J. K., Evolution in the intellectual structure of BIM research: a bibliometric analysis, Journal of Civil Engineering and Management, 23(8), 1060-1081, 2017.

[12] Liu, B., Sun, X. , Application analysis of BIM technology in metro rail transit, In IOP Conference Series: Earth and Environmental Science (Vol. 128, No. 1, p. 012028). IOP Publishing, 2018.

[13] Neves, J., Sampaio, Z., Vilela, M. , A case study of BIM implementation in rail track rehabilitation, Infrastructures, $4(1), 8$.

[14] Biancardo, S. A., Viscione, N., Cerbone, A., Dessì, E. , BIM-based design for road infrastructure: a critical focus on modeling guardrails and retaining walls, Infrastructures, 5(7), 59, 2020.

[15] Wu, I. C., Lu, S. R., Hsiung, B. C , A BIM-based monitoring system for urban deep excavation projects, Visualization in Engineering, 3(1), 1-11, 2015.

[16] Hou, B., CaO, Y., Lv, D., ZhaO, S. , Transit-Based Evacuation for Urban Rail Transit Line Emergency, Sustainability, 12(9), 3919, 2020.

[17] Bo YANG., Design and research of wireless communication system in urban rail transit, Hans Journal of Wireless Communications, 10(5), 43-48, 2020.

[18] Li, W., Zhou, M., Dong, H. , Cpt model-based prediction of the temporal and spatial distributions of passenger flow for urban rail transit under emergency conditions, Journal of Advanced Transportation, 2020(1), 1-11, 2020.

[19] Gao, H., Liu, S., CaO, G., ZhaO, P., Zhang, P, Big data analysis of beijing urban rail transit fares based on passenger flow, IEEE Access, PP(99), 1-1,2020.

[20] YANG, J., Analysis on the operation safety management mode of urban rail transit, Urban Transportation and Construction, $6(3), 42,2020$.

[21] LI, M., Yu, H., Jin, H., LiU, P. , Methodologies of safety risk control for China's metro construction based on BIM, Safety science, 110, 418-426.

[22] Chen, L., Shi, P., Tang, Q., Liu, W., Wu, Q., Development and application of a specification-compliant highway tunnel facility management system based on BIM, Tunnelling and Underground Space Technology, 97, 103262, 2020.

[23] LI, Y. W., CAO, K., Establishment and application of intelligent city building information model based on BP neural network model, Computer Communications, 153, 382-389, 2020.

[24] IsIKDAG, U., BIM and IoT: A synopsis from GIS perspective, The International Archives of Photogrammetry, Remote Sensing and Spatial Information Sciences, 40, 33, 2015.

[25] Sharma, A., Ansari, M. D., Kumar, R. , A comparative study of edge detectors in digital image processing, In 20174 th International Conference on Signal Processing, Computing and Control (ISPCC) (pp. 246-250). IEEE.

[26] Kaewunruen, S., Lian, Q. , Digital twin aided sustainability-based lifecycle management for railway turnout systems, Journal of Cleaner Production, 228, 1537-1551, 2019.

[27] Li, W., Zhou, M., H Dong. , Classifications of stations in urban rail transit based on the two-step cluster, Intelligent Automation and Soft Computing, 26(3), 531-538, 2020.

[28] Xue, G., Liu, S., Gong, D. , Identifying abnormal riding behavior in urban rail transit: a survey on "in-out" in the same subway station, IEEE Transactions on Intelligent Transportation Systems, PP(99), 1-13, 2020.

[29] Sharma, A., Kumar, R. , Risk-energy aware service level agreement assessment for computing quickest path in computer networks, International Journal of Reliability and Safety, 13(1-2), 96-124, 2019.

[30] Barazzetti, L., BAnfi, F. , BIM and GIS: when parametric modeling meets geospatial data, In ISPRS Workshop on Geospatial Solutions for Structural Design, Construction and Maintenance in Training Civil Engineers and Architects, Geospace 2017 (Vol. 4, No. 5W1, pp. 1-8).

[31] Wu, I. C., Lu, S. R., Hsiung, B. C. , A BIM-based monitoring system for urban deep excavation projects, Visualization in Engineering, 3(1), 1-11.

[32] Sharma, A., Kumar, R., Computation of the reliable and quickest data path for healthcare services by using service-level agreements and energy constraints, Arabian Journal for Science and Engineering, 44(11), 9087-9104, 2019.

Edited by: Pradeep Kumar Singh

Received: May 11, 2021

Accepted: Sep 20, 2021 